\title{
Wearable Device untuk Merekam Data Akselerasi Aktivitas Fisik Menggunakan Sensor Accelerometer
}

\author{
Made Liandana ${ }^{1}$, Bagus Made Sabda Nirmala ${ }^{2}$ \\ Sekolah Tinggi Manajemen Informatika dan Teknik Komputer (STMIK) STIKOM Bali1,2 \\ liandana@stikom-bali.ac.id ${ }^{1}$, sabda@stikom-bali.ac.id ${ }^{2}$
}

\begin{abstract}
Abstrak - Penelitian ini berfokus untuk merakam akselerasi sebagai akibat dari aktivitas fisik. Nilai akselerasi sebagai akibat dari suatu aktivitas memiliki pola tertentu sesuai dengan gerakan atau aktivitas yang dilakukan, pola dari akselerasi tersebut selanjutnya dapat diolah atau dikalkulasi untuk mengetahui jenis aktivitas yang dilakukan. Sebelum melakukan pengolahan data akselerasi maka diperlukan proses perekaman data, pada penelitian ini perekaman dilakukan dengan memasang perangkat wearable device pada pinggang sebelah kiri kemudian mengirimkan data tersebut ke komputer yang digunakan untuk merekam pola aktivitas. Wearable device yang dirancang terdiri dari: sensor accelerometer dengan menggunakan modul ADXL345, pembaca nilai sensor dengan menggunakan board Lilypad Arduino, pengirim data dengan menggunakan modul Bluetooth $\mathrm{HC}-05$, dan komputer penerima. Fungsi pengiriman data akselerasi, menampilkan nilai akselerasi, dan perekaman pola akselerasi untuk aktivitas berjalan, duduk, dan berdiri sudah dapat berfungsi dengan baik.
\end{abstract}

Kata kunci: wearable device, perekaman, aktivitas fisik.

\section{Latar Belakang}

Wearable device adalah menggabungkan teknologi elektronika atau komputer dalam sebuah benda sehingga dapat dikenakan atau digunakan pada bagain tubuh (Syauqy \& Maulana, 2018). Wearable device juga dapat didefinisikan sebagai perangkat elektronik dan komputer yang diintegrasikan ke dalam pakaian dan aksesoris lain yang dapat dipakai atau dikenakan ke bagian tubuh (Wright \& Keith, 2014). Wearable device dapat diterapkan pada berbagai bidang, seperti medis, hiburan, keamanan, hingga bidang komersial (Zhou et al., 2015). Secara fisik wearable device ini memiliki beragam bentuk, seperti gelang, jam tangan, lensa kontak, e-tekstil, kain pintar, topi, perhiasan seperti anting, cincin, dan bentuk lainnya (Syauqy \& Maulana, 2018). Smartwatch, smart eyewear, fitness tracker, smart clothing, wearable camera, dan wearable medical adalah beberapa contoh dari wearable device (Wright \& Keith, 2014), contoh wearable device tersebut cukup mudah kita temukan di pasaran.

Salah satu pengaplikasian dari wearable device adalah untuk melakukan deteksi aktivitas. Contoh aktivitas yang dapat dideteksi menggunakan wearable device, seperti aktivitas berjalan, berdiri, duduk, tidur, dan jatuh (Liu, Sohn, \& Kim, 2017)(Wu, Zhao, Zhao, \& Zhong, 2015). Ditinjau dari akurasi, informasi yang dihasilkan oleh wearable device dalam hal mendeteksi prilaku dan aktivitas manusia menunjukkan hasil yang cukup baik (Mukhopadhyay, 2015). Agar dapat mendeteksi aktivitas wearable device dapat dikenakan pada beberapa bagian tubuh penggunanya, misalnya di bagian dada (Prawiro, Yeh, Chou, Lee, \& Lin, 2016), pinggang (Wu et al., 2015), paha (Xiao \& Lu, 2015), kaki (Xing, Li, Hou, Zhang, \& Guo, 2017), dan pergelangan tangan (Nguyen, Fan, \& Shahabi, 2015).

Agar wearable device dapat melakukan deteksi aktivitas, tentunya tidak lepas dari peranan sensor. Studi menunjukkan sensor yang banyak digunakan untuk mendeteksi aktivitas adalah sensor jenis non visual, yaitu sensor accelerometer (Ranasinghe, Al MacHot, \& Mayr, 2016). Sensor accelerometer ini dapat dimanfaatkan untuk mendeteksi aktivitas sehari-hari (Liu et al., 2017). Accelerometer adalah sensor yang dapat digunakan untuk mengukur akselerasi atau percepatan. Ketika wearable device yang menggunakan sensor accelerometer dikenakan pada bagian tubuh pengguna mendapatkan gerakan atau getaran sebagai akibat dari suatu aktivitas, nilai akselerasi dari sensor akan berubah. Nilai akselerasi sebagai akibat dari suatu aktivitas memiliki pola tertentu sesuai dengan gerakan atau aktivitas yang dilakukan, pola dari akselerasi tersebut selanjutnya dapat diolah atau dikalkulasi untuk mengetahui jenis aktivitas yang dilakukan. Sebelum melakukan pengolahan data akselerasi maka diperlukan proses perekaman data, pada penelitian ini perekaman dilakukan dengan memasang perangkat wearable device pada pinggang sebelah kiri kemudian mengirimkan data tersebut ke komputer yang 
digunakan untuk merekam pola aktivitas. Pola aktivitas yang direkam adalah aktivitas duduk, berjalan, dan berbaring.

\section{Kajian Pustaka}

\section{a. Sensor Accelerometer ADXL345}

Modul sensor accelerometer ADXL345 (Nayyar \& Puri, 2016) memiliki sumbu $x, y$, dan z. Modul ini memiliki ukuran yang tipis, daya yang diperlukan rendah, dan memiliki resolusi 13 bit. Resolusi yang dimiliki mampu mengukur perubahan sudut dibawah 1 derajat. Modul sensor ini juga memiliki kemampuan pengukuran hingga mencapai $16 \mathrm{~g}$, dan kelurarannya dapat dipilih sesuai dengan kebutuhan mulai dari $2 \mathrm{~g}, 4 \mathrm{~g}, 8 \mathrm{~g}$, atau $16 \mathrm{~g}$. Data yang dihasilkan berupa data digital dengan format 16 bit dengan menggunakan bilangan komplemen kedua. Untuk menghubungkan modul sensor ini dengan perangkat lain seperti mikrokontroler, dapat menggunakan jalur komunikasi SPI dan I2C. Sensor ini dapat mengukur akselerasi dinamis yang dihasilkan oleh gerakan, dan akselerasi statis yang diakibatkan oleh gravitasi bumi. Dalam penerapannya modul sensor ini cocok digunakan untuk perangkat mobile.

\section{b. Arduino Lilypad}

Lilypad Arduino merupakan board yang didesain untuk aplikasi wearable board atau perangkat yang dapat dikenakan atau dipakai (Nayyar \& Puri, 2016) ("ArduinoLilyPad," n.d.). Sebagai sumber daya, board ini dapat menggunakan baterai yang diisi ulang, selain itu board ini dapat dihubungkan dengan sensor atau aktuator secara mudah. Lilypad Arduino terdiri dari beberapa ragam seperti: Lilypad Arduino USB, Lilypad Arduino Main Board, Lilypad Arduino Simple, dan Lilypad Arduino Simple Snap (Nayyar \& Puri, 2016). Tentunya masing-masing ragam atau jenis memiliki spesifikasi yang berbeda, misalnya Lilypad Arduino USB, menggunakan mikrokontroler ATmega32U4 yang terdiri dari 9 pin I/O, 4 input analog, 1 PWM output, 1 konektor JST (Japan Solderless Terminal), dan sebuah tombol reset. Lilypad Arduino USB dapat dihubungkan ke komputer menggunakan port Micro USB. Sedangkan untuk jenis Lilypad Arduino Main Board menggunakan mikrokontroler ATmega168V atau ATMega328V. Board ini terdiri dari 14. digital I/O, 6 analog input dan 6 PWM output, untuk memprogramnya diperlukan kabel FTDI. Untuk jenis Lilypad Arduino Simple dibangun menggunakan mikrokontroler ATmega328, terdiri dari 9 pin I/O, 4 pin analog, 5 output PWM, dan sebuah JST, sedangkan untuk memprogram board ini diperlukan kabel FTDI. Sedangkan jenis yang khusus untuk penerapan pada bahan-bahan tekstil dapat menggunakan jenis Lilypad Arduino Simple Snap yang berbasis mikrokontroler ATmega328.

\section{Perancangan Perangkat Keras \\ a. Diagram Blok Perangkat Keras}

Gambar 1 menunjukkan diagram blok dari wearable device dan hubungan masing-masing bagian. Sumber daya wearable device yang dirancang menggunakan baterai jenis lithium polymer, dengan voltase baterai sebesar 7.4 volt. Untuk menyesuaikan tegangan yang diperlukan oleh modul sensor ADXL345, Lillypad Arduino, dan modul bluetooth $\mathrm{HC}-05$ maka diperlukan rangkaian regulator. Modul sensor ADXL345 diberikan tegangan sebesar 3 volt, sedangkan modul bluetooth HC-05 dan Lilypad Arduino mengunakan tegangan 5 volt. Hasil akselerasi yang dihasilkan oleh modul sensor ADXL345 akan dibaca oleh mikrokontroler yang ada pada modul Lilypad Arduino, kemudian hasil pembacaannya tersebut akan diteruskan ke komputer perekam pola aktivitas melalui modul bluetooth HC-05. Modul ADXL345 dihubungkan dengan Lilypad Arduino menggunakan protokol komunikasi I2C, sedangkan Lilypad Arduino dan modul Bluetooth $\mathrm{HC}-05$ dihubungkan secara serial.

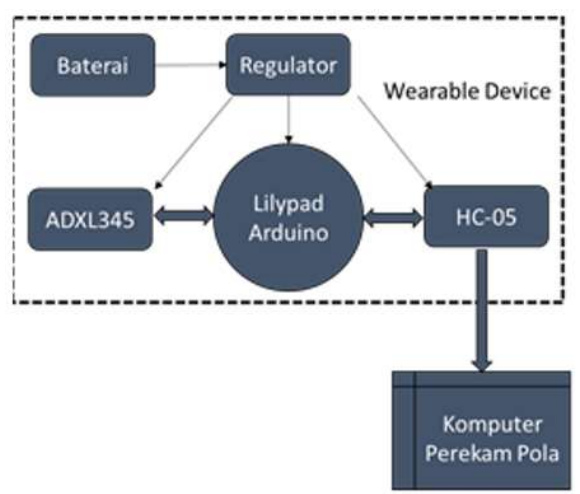

Gambar 1. Digram Blok Wearable Device

\section{b. Wearable Device}

Gambar 2 adalah wearable device yang dirancang dalam bentuk ikat pinggang. Wearable device ini memiliki panjang maksimal $110 \mathrm{~cm}$. Untuk kemudahan pemakaiannya maka bagian yang diikatkan pada pinggang (warna hitam) dibuat dinamis sehingga panjangnya dapat disesuaikan dengan ukuran pinggang pengguna.

Gambar 3 menunjukkan masing-masing modul ditempelkan pada bagian ikat pinggang (warna merah). Regulator, modul sensor ADXL345, modul Lilypad Arduino, dan modul bluetooth HC-05 ditempelkan dengan diikat menggunakan benang. Untuk baterai dibuatkan kantong khusus yang 
dapat dibongkar pasang sehingga lebih mudah dalam proses pengisian ulang baterai. Masingmasing modul dihubungkan dengan menggunakan konduktor berupa kabel.

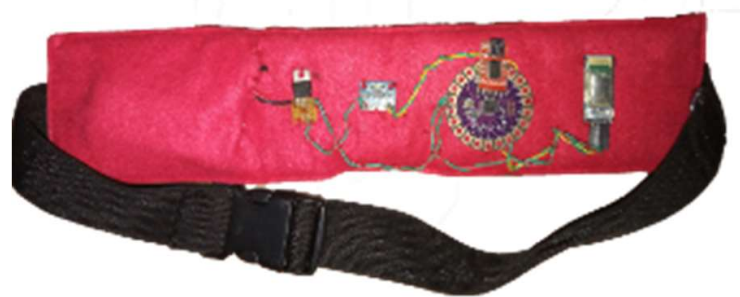

Gambar 2. Wearable Device

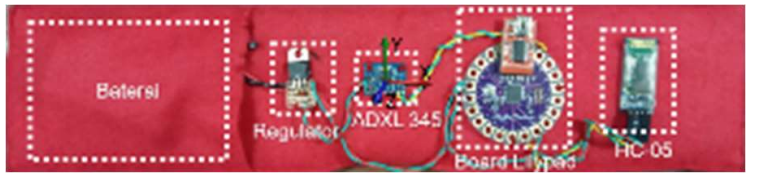

Gambar 3 Bagian-bagian dari Wearable Device

\section{c. Posisi Sumbu Sensor}

Modul sensor ADXL345 memiliki tiga sumbu, yaitu sumbu x, y, dan z. Arah masing-masing sumbu sensor accelerometer ketika pengguna yang mengenakan wearable device dalam posisi berdiri ditunjukkan pada Gambar 4. Saat pengguna berdiri, sumbu $\mathrm{x}$ berada pada posisi horisontal, sumbu y pada posisi vertikal, dan sumbu z mengarah ke samping.

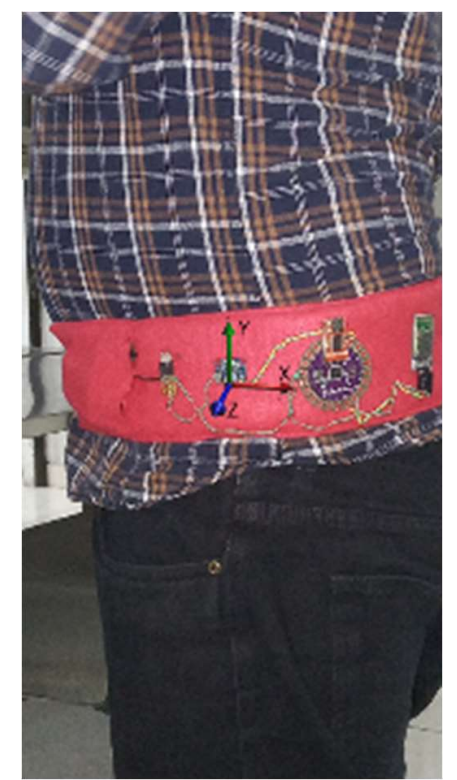

Gambar 4. Arah Sumbu Sensor Accelerometer

\section{Implementasi Sistem dan Hasil \\ a. Tampilan dari Sistem}

Akselerasi yang dihasilkan oleh wearable device sebagai akibat dari aktivitas fisik dikirim ke komputer penerima, proses pengiriman menggunakan komunikasi Bluetooth. Berikut adalah potongan kode program yang diimplementasikan ke dalam board Lilypad Arduino yang berfungsi untuk mengerim data akselerasi yang dihasilkan oleh modul sensor accelerometer ADXL345.

\begin{tabular}{|ll|}
\hline 1 & SoftwareSerial BTserial(10, 11); \\
2 & BTserial.print(X); \\
3 & BTserial.print(","); \\
4 & BTserial.print(Y); \\
5 & BTserial.print(","); \\
6 & BTserial.println(Z); \\
\hline
\end{tabular}

Pada komputer penerima terdapat aplikasi yang terdiri dari sejumlah menu. Menu tersebut yaitu Show Data Acceleration, Show Graphic Acceleration, Record Acceleration, Detecting Activity. Tampilan awal dari aplikasi penerima ditunjukkan pada Gambar 5.

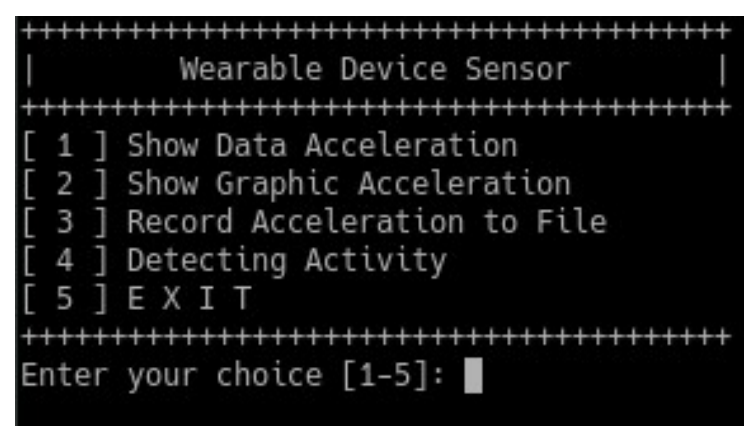

Gambar 5. Tampilan Program pada Komputer Penerima

Berikut adalah potongan kode program untuk menerima data akselerasi yang dikrimkan oleh board Lilypad Arduino melalui modul bluetooth HC05.

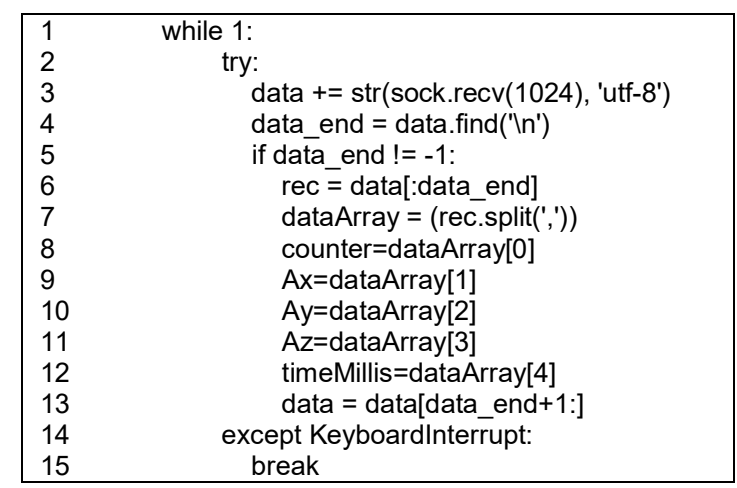

Menu Show Data Acceleration berfungsi untuk menampilkan nilai akselerasi yang dihasilkan oleh sensor accelerometer dalam bentuk teks. Tampilan dari Menu Show Data Acceleration tersebut ditunjukkan pada Gambar 6. Ketika Menu Show Graphic Acceleration dipilih hasilnya ditnjukkan seperti Gambar 7, menu ini berfungsi untuk 
menampilkan data akselerasi sensor dalam bentuk grafik untuk masing-masing sumbu sensor.

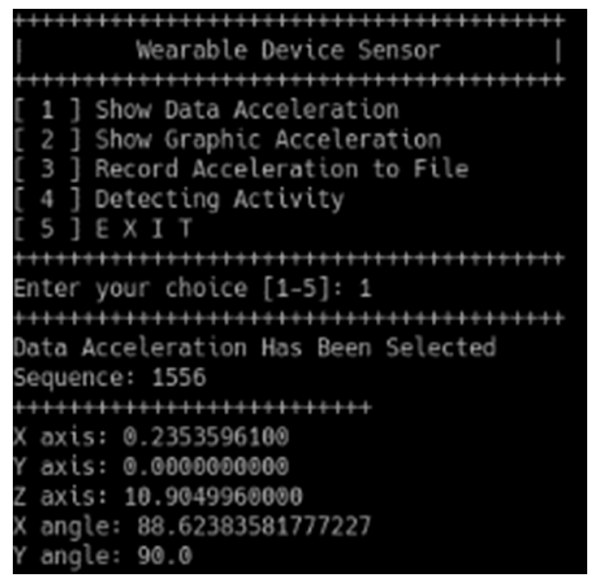

Gambar 6. Menu Show Data Acceleration
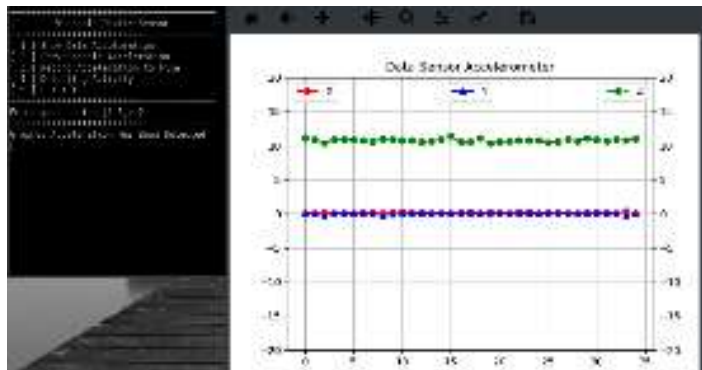

Gambar 7. Show Graphic Acceleration

Data akselerasi yang dihasilkan oleh sensor accelerometer sebagai akibat dari aktivitas fisik direkam dalam format .csv atau .txt, nilai yang direkam seperti profil pengguna, akselerasi sumbu $\mathrm{x}, \mathrm{y}, \mathrm{z}$, dan sudut kemiringan. Selanjutnya data hasil perekaman tersebut dapat dimanfaatkan untuk mengetahui pola dari aktivitas, seperti berjalan, duduk, dan berbaring. Untuk menjalankan fungsi ini dapat dilakukan dengan memilih Menu Record Acceleration to File. Tampilan dari menu ini ditunjukkan pada Gambar 8.

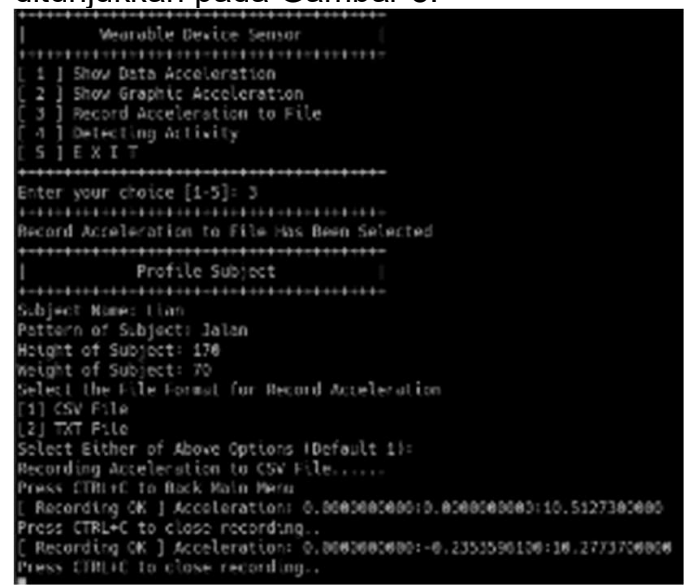

Gambar 8. Menu Record Acceleration to File

\section{b. Proses Perekaman Data}

Perekaman data akselerasi yang diakibatkan oleh aktivitas dilakukan untuk 3 aktivitas yaitu, berjalan, duduk, dan berbaring. Posisi dari aktivitas berjalan ditunjukkan pada Gambar 9, untuk posisi duduk ditunjukkan pada Gambar 10, dan untuk berbaring ditunjukkan pada Gambar 11. Saat perekaman wearable device diletakkan di bagian kiri pinggang. Saat melakukan perekaman akselerasi, pada aplikasi di komputer penerima dipilih Menu Record Acceleration to File seperti ditunjukkan pada Gambar 8.

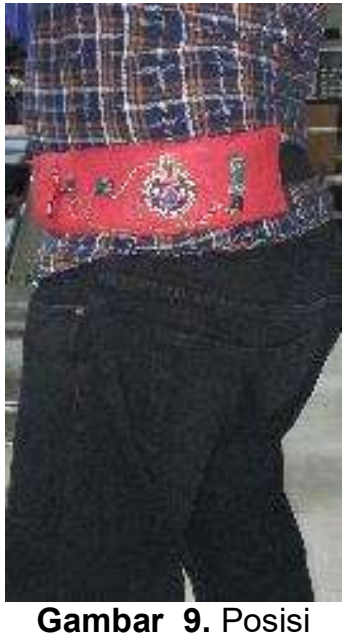

Gambar 9. Posisi Jalan

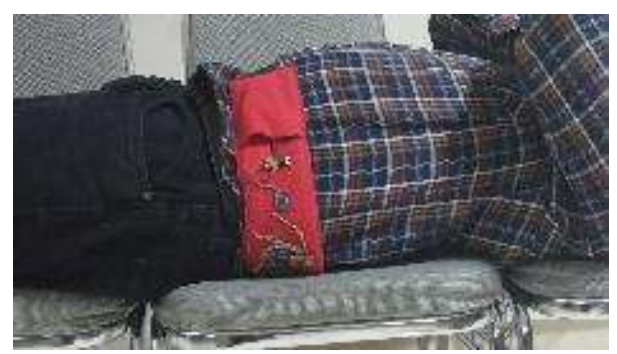

Gambar 11. Posisi Berbaring

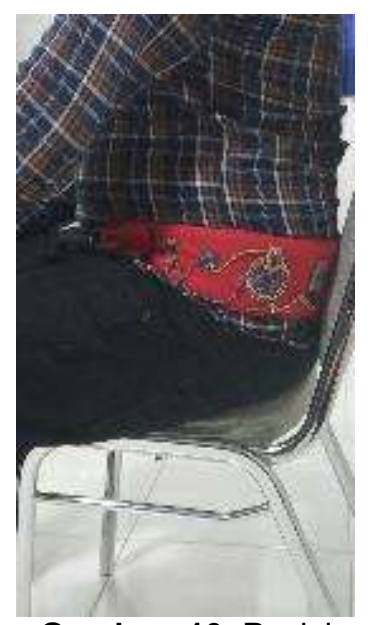

Gambar 10. Posisi Duduk
Hasil perekaman akselerasi aktvitias berjalan, duduk, dan berbaring yang disimpan dalam file .csv atau .txt selanjutnya dapat digunakan untuk mengetahui pola dari aktvitas fisik tersebut. Dari proses perekaman yang dilakukan diperoleh pola akselerasi seperti pada Gambar 12 sampai dengan Gambar 14. 


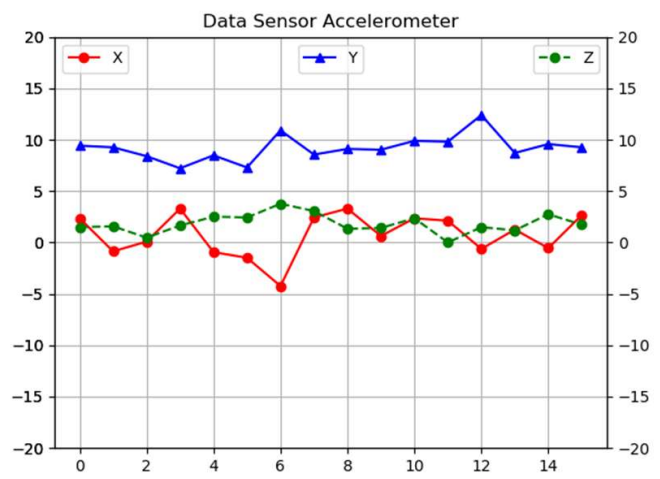

Gambar 12. Akselerasi ketika Berjalan

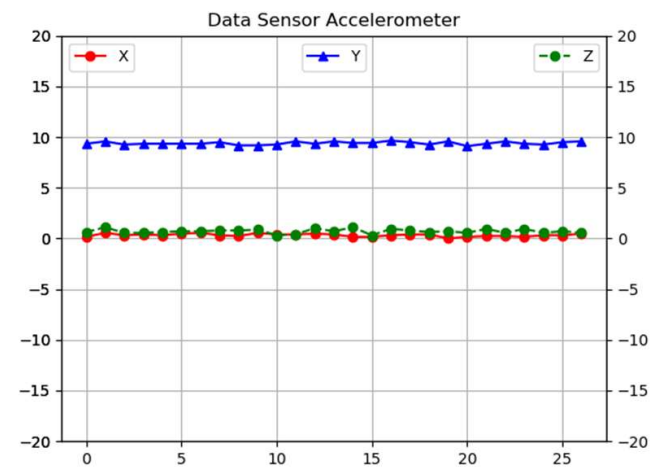

Gambar 13. Akselerasi ketika Duduk

Gambar 12 dan Gambar 13 merupakan pola akselerasi yang dihasilkan ketika aktivitas berjalan dan duduk. Dilihat dari sumbu sensor, posisi ketika duduk dan berjalan memiliki arah yang sama untuk masing-masing sumbu yaitu, sumbu $x$ berada pada posisi horisontal, sumbu y pada posisi vertikal, dan sumbu z mengarah ke samping Gambar 4. Namun jika dilihat dari pola akselerasi untuk sumbu $x, y$, dan z, aktivitas berjalan menunjukan pola yang lebih fluktuatif dibandingkan dengan aktivitas duduk, aktivitas duduk menunjukkan pola yang cenderung datar.

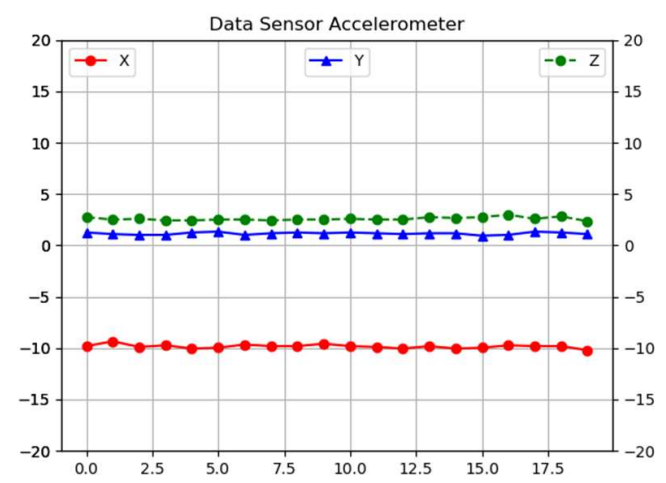

Gambar 14. Akselerasi ketika Berbaring
Sensor accelerometer mampu mendeteksi perubahan percepatan bumi, saat kondisi diam nilai akselerasi yang dialami oleh sensor accelerometer tersebut senilai dengan percepatan gravitasi bumi (Setiawan, Setiyono, \& Susilo, 2009). Arah sumbu $x$ pada sensor accelerometer ketika berbaring dengan posisi seperti Gambar 11 adalah mengarah ke atas, sehingga akan dipengaruhi oleh gaya gravitasi bumi. Nilai akselerasi sumbu x akan mendekati $9,8 \mathrm{~m} / \mathrm{s}^{2}$ seperti ditunjukkan pada grafik Gambar 14. Akan tetapi, jika dilihat dari lonjakan akselerasi nilainya cenderung datar.

\section{c. Pengujian Pengiriman Data}

Pengiriman data dari perangkat wearable device ke komputer penerima dilakukan dengan jarak kurang lebih 10 meter. Pada saat pengujian pengiriman data, wearable device mengirim data berupa akselerasi yang dihasilkan oleh sensor accelerometer ADXL345. Proses pengiriman data telah berhasil dilakukan, seperti ditunjukkan pada Tabel 1.

Tabel 1. Pengujian Pengiriman Data

\begin{tabular}{|c|c|c|c|c|}
\hline No & Jarak & $\begin{array}{l}\text { Data yang } \\
\text { dikirim }\end{array}$ & $\begin{array}{c}\text { Data yang } \\
\text { diterima }\end{array}$ & Hasil \\
\hline 1 & $\pm 1 \mathrm{~m}$ & $\begin{array}{c}0.7060788300 \\
0.9414384400 \\
5.256364800\end{array}$ & $\begin{array}{c}0.7060788300 \\
0.9414384400 \\
5.256364800\end{array}$ & $\begin{array}{c}\text { Data } \\
\text { Terkirim }\end{array}$ \\
\hline 2 & $\pm 2 \mathrm{~m}$ & $\begin{array}{c}0.8629852500, \\
1.7259705000, \\
11.9248880000\end{array}$ & $\begin{array}{c}0.8629852500 \\
1.7259705000 \\
11.9248880000\end{array}$ & $\begin{array}{c}\text { Data } \\
\text { Terkirim }\end{array}$ \\
\hline 3 & $\pm 3 \mathrm{~m}$ & $\begin{array}{c}-1.0983448000 \\
0.2353596100 \\
10.7480900000\end{array}$ & $\begin{array}{c}-1.0983448000 \\
0.2353596100 \\
10.7480900000\end{array}$ & $\begin{array}{c}\text { Data } \\
\text { Terkirim }\end{array}$ \\
\hline 4 & $\pm 4 \mathrm{~m}$ & $\begin{array}{c}-2.4320493000, \\
-2.1966896000 \\
9.4143848000\end{array}$ & $\begin{array}{c}-2.4320493000, \\
-2.1966896000 \\
9.4143848000\end{array}$ & $\begin{array}{c}\text { Data } \\
\text { Terkirim }\end{array}$ \\
\hline 5 & $\pm 5 \mathrm{~m}$ & $\begin{array}{c}-1.9613301000, \\
-2.2751429000 \\
6.2762566000\end{array}$ & $\begin{array}{c}-1.9613301000 \\
-2.2751429000 \\
6.2762566000\end{array}$ & $\begin{array}{c}\text { Data } \\
\text { Terkirim }\end{array}$ \\
\hline 6 & $\pm 6 \mathrm{~m}$ & $\begin{array}{c}4.1580200000, \\
-7.2176952000 \text {, } \\
7.8453202000\end{array}$ & $\begin{array}{c}4.1580200000 \\
-7.2176952000 \\
7.8453202000\end{array}$ & $\begin{array}{c}\text { Data } \\
\text { Terkirim }\end{array}$ \\
\hline 7 & $\pm 7 \mathrm{~m}$ & $\begin{array}{l}12.7878720000, \\
-5.1779113000, \\
10.1989170000\end{array}$ & $\begin{array}{c}4.1580200000 \\
-7.2176952000 \\
7.8453202000\end{array}$ & $\begin{array}{c}\text { Data } \\
\text { Terkirim }\end{array}$ \\
\hline 8 & $\pm 8 \mathrm{~m}$ & $\begin{array}{c}4.9425516000, \\
-2.6674089000, \\
9.7281971000\end{array}$ & $\begin{array}{c}12.7878720000, \\
-5.1779113000, \\
10.1989170000\end{array}$ & $\begin{array}{c}\text { Data } \\
\text { Terkirim }\end{array}$ \\
\hline 9 & $\pm 9 \mathrm{~m}$ & $\begin{array}{l}5.6486306000, \\
-1.9613301000, \\
11.6895280000\end{array}$ & $\begin{array}{c}5.6486306000 \\
-1.9613301000 \\
11.6895280000\end{array}$ & $\begin{array}{c}\text { Data } \\
\text { Terkirim }\end{array}$ \\
\hline
\end{tabular}




\begin{tabular}{|c|c|c|c|c|}
\hline 10 & \pm 10 & 5.8055367000, & 5.8055367000, & Data \\
& $\mathrm{m}$ & -1.3337045000, & -1.3337045000, & Terkirim \\
& & 8.0022268000 & 8.0022268000 & \\
\hline
\end{tabular}

\section{Kesimpulan}

Wearable device yang dirancang terdiri dari tiga bagian penting yaitu: sensor accelerometer dengan menggunakan modul ADXL345, pembaca nilai sensor dengan menggunakan board Lilypad Arduino, pengirim data dengan menggunakan modul Bluetooth $\mathrm{HC}-05$, dan komputer penerima. Dari hasil pengujian maka dapat disimpulkan sebagi berikut:

a. Fungsi pengiriman data dari wearable device ke komputer penerima sudah dapat berfungsi dengan baik dengan jarak pengujian $10 \mathrm{~m}$.

b. Pada komputer penerima fungsi menyajikan data akselerasi dari sensor accelerometer sudah dapat berfungsi dengan baik.

c. Perekaman data ke dalam format .CSV dan teks untuk aktivitas berjalan, duduk, dan berdiri yang dilakukan oleh komputer penerima sudah dapat berjalan dengan baik.

\section{Pustaka}

ArduinoLilyPad. (n.d.). Retrieved July 21, 2018, from

https://www.arduino.cc/en/Guide/ArduinoLily Pad

Liu, J., Sohn, J., \& Kim, S. (2017). Classification of Daily Activities for the Elderly Using Wearable Sensors. Journal of Healthcare Engineering, 2017, 1-7.

Mukhopadhyay, S. C. (2015). Wearable Sensors for Human Activity Monitoring: A Review. IEEE SENSORS JOURNAL, 15(3), 13211329.

Nayyar, A., \& Puri, V. (2016). A review of Arduino board's, Lilypad's \& Arduino shields. In 2016 International Conference on Computing for Sustainable Global Development (INDIACom) (pp. 1485-1492).

Nguyen, M., Fan, L., \& Shahabi, C. (2015). Activity Recognition Using Wrist-Worn Sensors for Human Performance Evaluation. In IEEE 15th International Conference on Data Mining Workshops (pp. 164-169).

Prawiro, E. A. P. J., Yeh, C.-I., Chou, N.-K., Lee, M.-W., \& Lin, Y.-H. (2016). Integrated Wearable System for Monitoring Heart Rate and Step during Physical Activity. Mobile Information Systems, 2016, 1-10.

Ranasinghe, S., Al MacHot, F., \& Mayr, H. C. (2016). A review on applications of activity recognition systems with regard to performance and evaluation. International Journal of Distributed Sensor Networks,
12(8).

https://doi.org/10.1177/1550147716665520

Setiawan, I., Setiyono, B., \& Susilo, T. B. (2009). Hasil Uji Kalibrasi Sensor Accelerometer ADXL335. TRANSMISI Jurnal Teknik Elektro, 11(3), 118-122.

Syauqy, D., \& Maulana, R. (2018). Implementasi Low Power Wearable Device Sebagai Heart Rate Monitor Dengan Metode State Machine. Jurnal Pengembangan Teknologi Informasi Dan IImu Komputer, 2(4), 1411-1418.

Wright, R., \& Keith, L. (2014). Wearable Technology: If the Tech Fits, Wear It. Journal of Electronic Resources in Medical Libraries, 11(4), 204-216. https://doi.org/10.1080/15424065.2014.9690 51

Wu, F., Zhao, H., Zhao, Y., \& Zhong, H. (2015). Development of a Wearable-Sensor-Based Fall Detection System. International Journal of Telemedicine and Applications, 2015, 111.

Xiao, W., \& Lu, Y. (2015). Daily Human Physical Activity Recognition Based on Kernel Discriminant Analysis and Extreme Learning Machine. Mathematical Problems in Engineering, 2015, 8.

Xing, H., Li, J., Hou, B., Zhang, Y., \& Guo, M. (2017). Pedestrian Stride Length Estimation from IMU Measurements and ANN Based Algorithm. Journal of Sensors, 2017. https://doi.org/10.1155/2017/6091261

Zhou, Y., Vongsa, D., Zhou, Y., Cheng, Z., Jing, L., \& Background, A. (2015). A Healthcare System for Detection and Analysis of Daily Activity based on Wearable Sensor and Smartphone. https://doi.org/10.1109/UICATC-ScalCom-CBDCom-IoP.2015.203 